\title{
MENINGKATAN KEMAMPUAN PUKULAN CHUDAN TSUKI DENGAN MENGGUNAKAN METODE LATIHAN PULL UP PADA DOJO KARATE CLUB KAJEN KABUPATEN PEKALONGAN
}

\author{
Lumeinthank Ade Prabowo', Danang Aji Setyawan², Yulia Ratimiasih ${ }^{3}$ \\ Fakultas Pendidikan IImu Penegetahuan Sosial dan Keolahragaan \\ Universitas PGRI Semarang \\ Email: ithankap61@gmail.com, danangpjkrupgris@gmail.com, \\ ratimiasihyulia@gmail.com
}

\begin{abstract}
ABSTRAK
Tujuan penelitian untuk mengetahui pengaruh latihan variasi Pull Upterhadap peningkatan kemampuan pukulan chudan tsuki serta kondisi fisik atlet. Metode penelitian yang digunakan adalah penelitian eksperimen dengan teknik pretest, treatment, posttest. Populasi dalam penelitian ini pada dojo Karate Club Kajen Kabupaten Pekalongan dengan jumlah sampel 18 atlet terdiri dari 7 putri dan 11 putra. Analisis data menggunakan perhitungan statistic dihitung menggunakan SPSS 22,0 dengan asumsi Uji Normalitas, Uji Homogenitas, Uji Hipotesis (uji t). Hasil penelitian diperoleh rata-rata hasil pretest kemampuan pukulan Chudan Tsukisebelum diberikan treatment (latihan Pull Up) adalah 9,6111 (36\%) dengan data (varian) 2,016 dan simpangan baku (standar deviasi) 1,41998. Sedangkan rata-rata hasil posttest kemampuan pukulan Chudan Tsukisetelah diberikan treatment (latihan Pull Up) adalah 17,111 (64\%) dengan keragaman data (varian) 6,810 dan simpangan baku (standar deviasi) 2,60969. Maka terjadi peningkatan pukulan Chudan Tsukisebesar 28\%. Deskripsi hasil treatment (latihan Pull Up) diperoleh skor rata-rata lebih dari 10 dimana skor terendah sebesar 13 dan skor tertinggi 27. Secara keseluruhan selama 16 kali pertemuan terjadi naik turun (flukuatif) hasil skornya. Berdasarkan dari tujuan penelitian dan hasil penelitian yang telah diuraikan diatas, maka diperoleh kesimpulan bahwa pemberian latihan Pull Up berpengaruh dalam meningkatkan kemampuan pukulan Chudan Tsuki. Pada hasil penelitian menyarankan untuk dapat memasukan latihan Pull Up dalam program latihan karate dan menyediakan sarana dan prasarana yang lebih baik agar atlet dapat berlatih secara efektif dan semangat ntuk berlatih.
\end{abstract}

\section{Kata Kunci : Pukulan Chudan Tsuki, Latihan Pull Up, Karate}

Abstrack
The aim of the study was to determine the effect of the Pull Up variation exercise on
increasing the ability of Tsuki's chudan punch and the athlete's physical condition. The
research method used was experimental research with pretest, treatment, posttest. The
population in this study was at the Karate Club Kajen dojo in Pekalongan Regency with a
sample of 18 athletes consisting of 7 daughters and 11 sons. Data analysis using statistical
calculations was calculated using SPSS 22.0 assuming the Normality Test, Homogeneity
Test, Hypothesis Test (t test). The results obtained by the average results of Chudan Tsuki's
pretest ability before being given treatment (Pull Up training) is 9.6111 (36\%) with data
(variant) 2.016 and standard deviation (standard deviation) 1.41998. While the average
posttest results of Chudan Tsuki's punch ability after being given treatment (Pull Up training)


is 17.111 (64\%) with a diversity of data (variant) 6.810 and standard deviation (standard deviation) 2.60969. Then Chudan Tsuki's punch increased by 28\%. The results of the treatment description (Pull Up training) obtained an average score of more than 10 where the lowest score was 13 and the highest score was 27. Overall for 16 meetings there were fluctuations in the score. Based on the research objectives and the results of the research described

above, the conclusion is that the exercise of Pull Up influences Chudan Tsuki's ability to punch. The results of the study suggest to be able to include Pull Up exercises in karate training programs and provide better facilities and infrastructure so that athletes can practice effectively and have the spirit to practice.

Keywoard : Chudan Tsuki Blow, Exercise Pull Up, Karate.

\section{PENDAHULUAN}

Olahraga merupakan salah satu alternatif paling efektif dan aman untuk memperoleh kebugaran jasmani dan kesehatan. Untuk mendapatkan kebugaran jasmani dan kesehatan, olahraga atau aktifitas fisik merupakan salah satu kegiatan yang perlu dilakukan oleh setiap orang. Selain itu, olahraga juga dapat meningkatkan derajat seseorang yakni dengan berbagai prestasi yang diraih melalui kejuaraan multi event (Aziz : 2018). Kegiatan olahraga merupakan bagian yang tidak terpisahkan dari semua aspek kehidupan manusia yang selalu beriringan dan saling mempengaruhi. Ini dapat dilihat dari keberadaan manusia berkembang yang selalu diikuti dengan perkembangan bidang olahraga. Pada prinsipnya, manusia melakukan aktivitas olahraga dengan tujuan untuk mencapai tingkat kesegaran jasmani tertentu, mengisi waktu senggang dan meningkatkan pertahanan diri melalui olahraga bela diri. (Santos : 2016). Bela diri adalah salah satu olahraga yang memiliki tujuan untuk membela diri dari suatu tindak kejahatan atau kriminal disuatu tempat tertentu. Menurut Hairan (2014) yang dikemukakan oleh Sena Dwi Laksono bahwa pengertian bela diri adalah sebagai berikut : Ada dua pengertian bela diri yakni secara sempit dan secara luas, beladiri dalam arti sempit adalah seni bertarung yang secara mendasar dibentuk oleh Dharma Taishi (Tatmo Cawsu), Pendeta Budha Generasi ke28. Pada tahun 550 Masehi, ia bepergian ke Cina dari India untuk mengajarkan agama Budha. Disamping itu, ia juga mengajarkan Indo Kempo (Seni Bertarung Alalndia). Hal ini penting diajarkan karena jaman dahulu pendeta Budha sangat sering berpergian dari Cina ke India atau sebaliknya yang bertujuan untuk belajar agama Budha.

Karate adalah seni bela diri yang berasal dari jepang. Karate pertama kali lahir pada tahun 1921. Karate berasal dari kata kara yang artinya kosong, sedangkan kata te yang artinya tangan. Karate dapat disebut sebagai olahraga bela diri tangan kosong. Menurut Zen-Nippon Karatedo Renmei/Japan Karatedo Federation(JKF) dan World Karate-do Federation(WKF), yang dianggap sebagai aliran karate yang utama yaitu shotokan, goju-ryu, shito-ryu, wado-ryu, keempat aliran tersebut diakui sebagai gaya karate yang utama karena turut serta dalam pembentukan JKF dan WKF. Azis (2018). Chudan Tsuki adalah pukulan kearah ulu hati (tengah) posisi badan tegak dan telapak tangan harus mengepal teknik yang dilakukan 
dengan sikap kuda-kuda, meluruskan siku dan merentangkan lengan bawah kedepan untuk menyerang lawan (Phang Victorianus, $2012: 24$ ) dalam skripsi Laksono (2017). Menurut Mustaqim (2018) Pull Up merupakan sebuah bentuk latihan yang dilaksanakan dengan menggunakan alat, yaitu palang kayu atau palang besi. Tujuan utama dari latihan ini adalah untuk melatih kekuatan otot tangan. Pelatihan kekuatan otot lengan dengan gerakan pull up dapat memberikan pengaruh yang signifikan terhadap kekuatan pukulan pada beladiri karate selain itu melatih kondisi fisik pada atlet karate karena terdapat beban yang harus diterima sesuai kemampuanya. Untuk mengetahui kemampuan pukulan chudan tsuki atlet karate maka peneliti akan melakukan tes di salah satu club karate di Kabupaten Pekalongan yang bernama Karate Club Kajen. Dari hasil observasi tersebut menyebutkan bahwa hal-hal yang kurang mendukung pelaksanaan pukulan chudan tsuki atau gyaku tsuki adalah: Banyak karateka yang belum dilatih teknik pernafasan (Hara) dengan benar dan baik,

Belum maksimalnya perputaran pinggul dalam membantu gerak bahu dan lengan saat memukul, Banyak penekanan power/tenaga diawal gerakan dan bukan diakhir gerakan/benturan/impact, Reaksi tangan, power dan kecepatan yang masih lemah pada saat melakukan pukulan chudan tsuki atau gyaku tsuki, Kurang nya bentuk kihon (teknik dasar) yang baik dan benar, Unsur kebugaran karateka pada saat berlatih kurang baik. Dari hasil observasi yang dilakukan oleh peneliti dalam melakukan kombinasi pukulan chudan tsuki pada karate-ka Club
Kajen Kabupaten Pekalongan, dipandang masih belum mencapai kemampuan yang maksimal dan masih banyak faktor yang kurang mendukung dalam melakukan pukulan chudan tsuki. Sehingga dalam melakukan kombinasi pukulan chudan tsuki perlu adanya latihan beban untuk lengan dan memperhatikan kemampuan terhadap pukulan yang menggunakan tangan. Sehingga peneliti perlu mengadakan penelitian untuk mencari jalan keluar faktor-faktor apa saja yang masih dapat diperbaiki untuk memaksimalkan hasil kemampuan pukulan chudan tsuki. Untuk itu, peneliti melakukan penelitian dengan judul : "Meningkatkan Kemampuan Pukulan Chudan Tsuki Dengan Menggunakan Metode Latihan Pull Up Pada Dojo Karate Club Kajen Kabupaten Pekalongan" pada atlet karate umur 16-17 tahun pada nomor kumite $60 \mathrm{~kg}$ kadet kategori SMA. Didalam penelitian ini berharap dengan latihan komponen fisik power otot lengan metode latihan Pull Up dapat meningkatkan kemampuan pukulan Chudan Tsuki dan unsur kebugaran jasmani atlet terutama kondisi fisik bisa lebih meningkat. Adapun keterangan nilai terendah yang telah dicantumkan pada tabel sebagai berikut:

\section{HASIL DAN PEMBAHASAN}

Penelitian ini dilakukan pada Dojo Karate Club Kajen Kabupaten Pekalongan dengan subjek penelitian yaitu atlet karate umur 16-17 tahun pada nomor kumite $-60 \mathrm{~kg}$ kadet kategori SMA sebanyak 18 orang dengan 7 atlet putri dan 11 atlet putra. Dalam penelitian ini dilakukan untuk mengetahui apakah metode latihan Pull Up dapat meningkatkan 
kemampuan pukulan Chudan Tsuki. Latihan (treatment) yang diberikan pada atlet karate dalam penelitian ini yaitu latihan kekuatan otot pull up dengan 16 kali pertemuan agar dapat diketahui pengaruhnya dalam peningkatan kemampuan pukulan Chudan Tsuki. Uji normalitas merupakan salah satu tahapan yang dilakukan sebelum dilakukannya uji hipotesis. Uji normalitas dengan uji Liliefors dilakukan untuk mengetahui sampel berasal dari distribusi normal atau tidak. Uji homogenitas dilakukan untuk mengetahui apakah data pretest (sebelum diberikan treatment) dan data posttest (setelah diberikan treatment) memiliki varians yang sama atau tidak. Untuk menguji homogenitas dari sampel digunakan uji levene test. Uji perbedaan data hasil pretest dan posttest kemapuan pukulan Chudan Tsuki dimaksudkan untuk mengetahui apakah pemberian latihan kekuatan otot pull up berpengaruh terhadap peningkatan kemampuan pukulan Chudan Tsuki di Karate Club Kajen Kabupaten Pekalongan. Uji yang digunakan adalah Paired Sample T-Test (Uji Beda 2 Mean Berpasangan). Berdasarkan hasil olah data SPSS 22,0 2019, diperoleh hasil uji normalitas bahwa pada data pretest diperoleh nilai Sig. $=0,320$ dan data posttest diperoleh nilai Sig. $=0,815$.

\section{SIMPULAN DAN SARAN KESIMPULAN}

penelitian $\begin{array}{cc}\text { Berdasarkan dari tujuan } \\ \text { untuk mengetahui }\end{array}$ peningkatan kemampuan pukulan chudan tsuki menggunakan metode latihan pull up pada atlet karate di dojo Kajen Karate Club Kabupaten Pekalongan, serta berdasarkan hasil penelitian yang telah diuraikan diatas, maka dapat ditarik kesimpulan bahwa:
Karena semua nilai Sig. $>\alpha=0,05$. Sehingga dapat disimpulkan bahwa data pretest dan posttest berasal dari distribusi normal. Asumsi data berdistribusi normal terpenuhi. Berdasarkan hasil olah data SPSS 22,0 diperoleh uji homogenitas nilai Sig. $(0,051)>\alpha(0,05)$. Maka dapat disimpulkan bahwa data pretest dan posttest adalah homogen atau memiliki varians (keanekaragaman data) yang sama. Sehingga varians populasi homogen. Berdasarkan hasil olah data SPSS 22,0 diperoleh uji hipotesis nilai Sig. $(0,000)<\alpha(0,05)$. $\mathrm{H}_{\mathrm{a}}$ diterima, Sehingga ada perbedaan yang signifikan hasil pretest dan posttest latihan otot pull up terhadap kemampuan pukulanChudan Tsuki. Dapat dilihat dari peningkatan rataratanya, rata-rata sebelum diberikan treatment (pretest) yaitu 9,611 dan rata-rata setelah diberikan treatment (Posttest) yaitu 17,111. Dalam penelitian ini terjadi peningkatan sebesar $28 \%$ dari hasil pretest ke posttest. Latihan kekuatan otot pull up dapat direkomendasikan dan efektif untuk meningkatkan kemampuan pukulan chudan tsukiserta meningkatkan kondisi fisik para atlet Karate Kajen Kabupaten Pekalongan.

Ada perbedaan yang signifikan hasil pretest dan posttest dalam latihan pull up terhadap kemampuan pukulan chudan tsuki. Jadi dapat dikatakan ada perbedaan yang signifikan hasil pretest dan posttest dapat dilihat dari meningkatnya kemampuan pukulan chudan tsuki sebelum diberikan treatment nilai rata-rata (mean) yaitu 9,6111 setelah diberikan treatment nilai rata-rata (mean) menjadi 17,111. Sehingga dapat disimpulkan bahwa 
pemberian latihan pull up (treatment) berpengaruh dalam meningkatkan kemampuan pukulan chudan tsuki.Dalam penelitian ini terjadi peningkatkan sebesar $28 \%$ dari pretest ke posttest. Berdasarkan grafik deskripsi hasil treatment diatas dapat dilihat bahwa score hasil latihan pull up rata-rata lebih dari 10 secara keseluruhan. Sehingga masih termasuk dalam kategori sedang. Dimana rata-rata nilai terendah terjadi pada siklus 1 pertemuan ke 4 yaitu latihan behind the neck pull up dengan nilai 13. Sedangkan hasil rata-rata tertinggi terjadi pada siklus 4 pertemuan 14 yaitu latihan chin up dengan nilai 27. Secara keseluruhan selama 16 kali pertemuan latihan kekuatan pull up terjadi naik turun (fluktuatif) hasil skor nya. Dari hasil penelitian diatas berdasarkan Uji Normalitas diperoleh hasil bahwa data pretest diperoleh nilai Sig. $=0,320$ (.320) dan data posttest diperoleh nilai Sig. $=0.815(.815)$ karena semua nilai Sig. $>\alpha=0,05$ dapat disimpulkan bahwa data pretest dan posttest berasal dari distribusi normal. Asumsi dan berdistribusi terpenuhi. Berdasarkan Uji Homogenitas diperoleh nilai Sig. $(0.051)>a(0,05)$ maka disimpulkan data pretest dan posttest adalah homogen atau varian yang sama. Berdasarkan Uji Hipotesis diperoleh nilai Sig. $(0,000)<\alpha(0,05)$ sehingga ada perbedaan yang signifikan hasil pretest dan posttest latihan otot pull up terhadap kemampuan pukulan chudan tsuki.

\section{SARAN}

Mengacu pada hasil penelitian menyarankan : Bagi pelatih, dapat memasukan latihan pull up sebagai acuan untuk meningkat kemampuan memukul chudan tsuki dalam program latihan karate. Bagi club, tempat (dojo) dapat menyediakan sarana dan prasarana yang lebih baik agar atlet dapat berlatih secara efektif dan semangat untuk berlatih. Bagi atlet, dengan hasil penelitian atlet dapat mengetahui dan lebih berusaha untuk meningkatkan latihan pull up agar kemampuan kihon dan kondisi fisik bisa lebih baik.

\section{DAFTAR PUSTAKA}

Azis. 2018. Pengembangan Buku Panduan Teknik Dasar (Kihon, Kata, Kumite)Untuk Perguruan Karate Gokasi. Skripsi. Yogyakarta Universitas Negeri Yogyakarta

Dwikusworo, E.P. 2010. Tes Pengukuran Dan Evaluasi Olahraga. Semarang:Widya Karya.

Erliana, M. 2015. "Pengaruh Latihan Kekuatan Otot Lengan Melalui PullUp Terhadap Peningkatan Speed Track Atlet Federasi Panjat Tebing Indonesia Banjarbaru. Jurnal Multirateral. 14 (1) 1-6.

Hidayat, R,dkk. 2018. "Pengaruh Metode Latihan Push Up Dan Latihan Clapping

Push Up Terhadap Daya Ledak Otot Lengan Study Kasus Pada Atlet Pencak Silat Tuah Pandeka Rajo. Jurnal Stamina. 1 (1) 311324.

Laksono. 2017. Hubungan Reaksi Dan Kekuatan Otot Lengan Dengan Kecepatan Pukulan Chudan Tsuki Pada Siswa Ekstrakulikuler Karate SMP IT Permata Bunda Bandar 
Lampung. Skripsi. Lampung : Ekstrakulikuler Karate SMP IT Permata Bunda.

Manullang, J.G,dkk. 2016. "Pengaruh Metode Latihan Dan Power Lengan Terhadap Kecepatan Pukulan Gyaku Tsuki Chudan Pada Cabang Olahraga Karate Dojo Khusus UNIMED. Journal Of Physical Education And Sports. 3 (2) 105-107.

Mustaqim, E.A. 2018. "Pengaruh Latihan Push Up Dan Pull Up Terhadap Hasil Flying Shoot Dalam Permainan Bola Tangan UNISMA Bekasi. Jurnal Genta Mulia. 9 (1) 5262.

Pranata, L.D, dkk. 2017. "Pengaruh Latihan Beban Gaya-Pegas Terhadap Kecepatan Pukulan Kumite Gyaku Tsuki Untuk Atlet Karate Inkanas Kota Bengkulu. Jurnal IImiah Pendidikan Jasmani. 1 (2) 106-110.

Purba, P.H. 2017. "Perbedaan Pengaruh Latihan Menggunakan Karet Dengan Menggunakan Dumbell $1 \mathrm{Kg}$ Terhadap Kecepatan Pukulan Oi Tsuki Chudan Pada Atlet Karate Putra Perguruan Wadokai Dojo SMA Negeri 11 Medan Tahun 2017. Jurnal IImu Keolahragaan. 2 (1) 60-71.

\begin{tabular}{|c|c|}
\hline intos. & $\begin{array}{l}\text { 2016. Pengaruh Metode } \\
\text { Latihan Beban Dan } \\
\text { Kecepatan Reaksi Tangan } \\
\text { Terhadap Kecepatan } \\
\text { Pukulan Kizami-Gyaku Tsuk } \\
\text { Pada Karateka Inkanas } \\
\text { UNM. Skripsi. Makassar } \\
\text { Unversitas Negeri Makassar. }\end{array}$ \\
\hline & 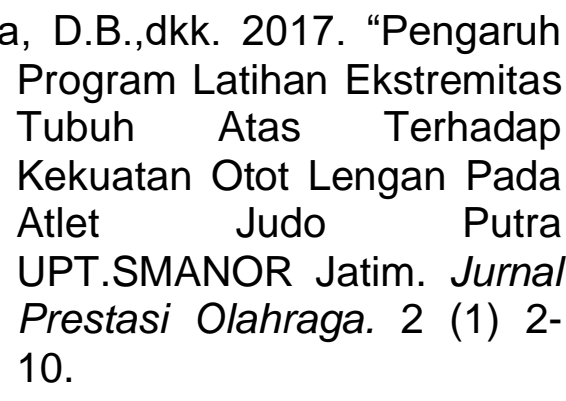 \\
\hline Sunarno & 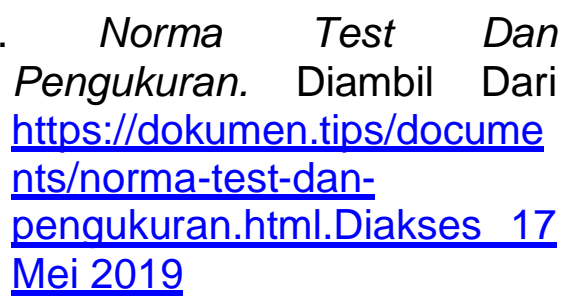 \\
\hline aksor & $\begin{array}{l}\text { 2017. Norma test dan } \\
\text { Pengukuran pukulan Chudan } \\
\text { Tsuki. Skripsi. Lampung : } \\
\text { Ekstrakulikuler Karate SMP } \\
\text { IT Permata Bunda }\end{array}$ \\
\hline
\end{tabular}

Sugiyono. 2015. Metode Penelitian Kuantitatif Kualitatif dan $R \& D$. Bandung: Alfabeta Hernado, dkk 2017. "Pengaruh Metode Latihan dan Power Otot Lengan terhadap Hasil Tolak Peluru". Journal of Physical Education and Sports. 6 (1) 